\title{
Levels, Sources and Risk Characterization of Organochlorine Pesticides in Beer Samples from Romania
}

\author{
SEMAGHIUL BIRGHILA ${ }^{1}$, MIHAELA MIRELA BRATU ${ }^{2 *}$, VALENTINA COATU $^{3}$, \\ NICOLETA-ALEXANDRA DAMIR ${ }^{3}$ \\ ${ }^{1}$ Ovidius University of Constanta, Department of Chemistry and Chemical Engineering, 124 Mamaia Av., 900527, \\ Constanta, Romania \\ ${ }^{2}$ Ovidius University of Constanta, Department of Pharmaceutical Sciences II, 1Universității Alley, Campus, 900470, \\ Constanta, Romania \\ ${ }^{3}$ Grigore Antipa National Institute for Marine Research and Development, NIMRD, 300 Mamaia Blvd., 900001, Constanta, \\ Romania
}

The present study describes the analysis of nine organochlorine pesticides (OCPs) occurrence in twenty beer samples commercially marketed and widely consumed in Romania. Levels of these compounds were determined by gas chromatography with electron capture detector (GC-ECD). The results indicated that $20 \%$ of the examined samples were contaminated with one OCP residues, while $45 \%$ of samples have presented multiple pesticides. Among individual compounds, $\gamma$-HCH (Lindane) and p,p DDE were the main contributors to the total OCP residues, suggesting a long-time persistence of these pesticides in soil, recent usage or uncontrolled penetration from some sources. The contamination frequency with the different OCPS of analysed samples was in the following order: $D D T s>$ Driens $>$ Heptachlor $>$ Lindane $>H C B$. The average lifetime of a daily dose (LADD) for the total compounds under study, were below the acceptable daily intake (ADI) for individual compounds,

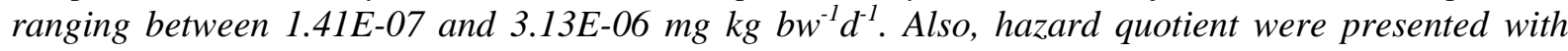
very low values $(H Q<1)$, suggesting that, in the analysed samples, the OCP residues represent no threat to human health.

Keywords: organochlorine pesticide, beer sample, CG-ECD, hazard quotient

Nowadays, beer is the most consumed low alcoholic beverage worldwide. It is obtained following the yeast alcoholic fermentation of the brewing wort, consisting of barley malt, hops and water.

The raw materials for beer production are an attractive source of nutrients for insects and microbial pathogens. The high moisture content of barley grains favours fungus attacks during storage. Most fungi produce secondary metabolites, some of which affect the quality of beer. This is the reason why pesticides are widely used in different combinations at many stages of cultivation and during post-harvest storage, as well. The residue pesticides may remain in the beer produced from the treated ingredients, although the residues may also come from the soil itself or the water that is used.

Generally, the brewers should pay special attention to the residues of hydrophobic pesticides, due to their remanence. In addition, brewers should control the residues of hydrophilic pesticides, as they can be carried over into beer [1]. Furthermore, the pesticide residues can have a negative influence on the beer's flavour, colour, sugar content, acidity and flavonoid contents. Thus, the monitoring of pesticide content during the brewing process is essential in order to obtain a safe product.

Pesticides affect human beings and may have various harmful impacts on the environment. These substances can be dangerous for human health when the exposure degree exceeds the safety levels. The increased amount of pesticides used in agriculture and the continuous presence of pesticides in aquatic environments determined the European Union to consider necessary the introduction of clear rules concerning their use [2].

Recently, the European Union policy makers have discussed a wide pesticide tax scheme as a market-based policy tool, taking into account the negative spill-over determined by the continuous use of chemical inputs $[3,4]$.

Organochlorine pesticides (OCPs) are the most persistent organic contaminants in the environment, being classified as persistent organic pollutants (POPs) due to their persistence and bioaccumulation in the environment [5]. Most of organochlorine pesticides have been banned in many countries because of their toxicity risk for humans and stability in the environment (up to 30 years); their residues still appear as contaminants in food as well as in the environment [6].

\footnotetext{
*email: mmbratu@hotmail.com
} 
OCPs are characterized by high persistence, diffusion in the environment, low polarity and high lipid solubility [7]. The lipophilic nature of OCPs together with its low reactivity to light and chemicals and its low biological degradation rates, have determined the OCPs accumulation in biological tissues.

The occurrence of OCPs has been reported in many foods including fruits and vegetables [8-11].

The aim of this study includes (i) the determination of organochlorine pesticides levels (OCPs) in the most consumed industrial beer on the Romanian market, (ii) identification of organochlorine pesticides sources (iii) evaluation of the health risk level associated with OCPs exposure through beer consumption.

\section{Experimental part}

Reagents

Analytical standards of aldrin, endrin, dieldrin, hexachlor-benzene (HCB), heptachlor, $\alpha, \beta, \gamma$-hexachlor-ciclohexane $(\mathrm{HCH})$, p,p DDE, p,p' DDD, p,p' DDT were obtained from Dr. Ehrenstorfer (Ausberg, Germany). Purities of pesticide standards were greater than $99 \%$. Pesticide-grade ethyl acetate, acetone, n-hexane and anhydrous sodium sulphate were obtained from Merck (Darmstadt, Germany). Helium and nitrogen gases of 99.99\% purity were purchased from Fluka (Switzerland). Deionised water was used during the entire experiment.

For clean-up step we used a usual sorbent for organochlorine pesticides, florosil from Fluka (Switzerland) after activation $12 \mathrm{~h}$ at $130^{\circ} \mathrm{C}$, before use. Anhydrous sodium sulphate activated at $200^{\circ} \mathrm{C}$, was used to retain impurities. As eluents, we used n-hexan supplied by Merck (Darmstadt, Germany) and dichloromethane supplied by J.T.Baker.

\section{Instrumental analysis}

OCPs were analysed using a Hewlett-Packard 5890 gas chromatograph (GC), equipped with an electron capture detector (ECD). The GC was equipped with a Hewlett-Packard -5-fused-silica capillary column $(29.6 \mathrm{~m} \mathrm{x} 0.32 \mathrm{~mm} \times$ $0.25 \mu \mathrm{m})$. The carrier gas which has been used was helium maintained at a flow rate of $1.86 \mathrm{ml} / \mathrm{min}$ and nitrogen makes-up gas at 40 psi. The injector and detector temperature was $250{ }^{\circ} \mathrm{C}$. The initial temperature was $60^{\circ} \mathrm{C}$; after that, the temperature was increased to $300{ }^{\circ} \mathrm{C}$ at a ramp rate of $20^{\circ} \mathrm{C} / \mathrm{min}$ and then held for $10 \mathrm{~min}$.

\section{Samples}

Twenty of the most popular beer widely consumed in Romania, purchased from the local supermarket, had been selected for this study. All analysed beer brands have an alcohol content raging between 4-4.5\%, according to the specifications on the label. The manufacturing date of all samples was year 2017 and the best before date was 180 days or 360 days.

\section{Extraction}

Samples of $100 \mathrm{~mL}$ beer have been extracted in an ultrasound bath with $3 \times 10 \mathrm{~mL}$ hexane for $10 \mathrm{~min}$, then the extracts were centrifuged for $10 \mathrm{~min}$ at $9000 \mathrm{rcf}$ and the supernatants were collected and filtered. After that, $\sim 30 \mathrm{ml}$ of the filtered extract was applied to $5 \mathrm{~g}$ of activated florisil column and topped with $1 \mathrm{~g}$ of anhydrous sodium sulphate, which was prewashed with n-hexan. The columns were eluted with n-hexan plus dichlormethane (3:1). Each fraction was concentrated to $1 \mathrm{ml}$ volume using the Kuderna-Danish concentrator. The concentrated aliquot was blown down with nitrogen, the internal standard 2,4,5 trichlorobiphenyl (IS) was added and the final volume was injected.

\section{Quality control}

Calibration standard curves were built and OCP residues were determined by comparison of the retention time and peak areas of the sample chromatogram with those of standard solutions run under the same working conditions. Recovery study was performed by adding the pesticides to beer samples at the indicated fortification level and the recovery values were calculated from calibration curves.

Detection limits of the method were found by determining the lowest concentrations of the residues in each of the matrices that could be reproducibly measured at the work conditions of the GC. The correlation coefficients derived from the linear regressions were higher than 0.9600 , which show a strong correlation between the peak height ratios and the concentrations.

The detection limits were low and ranged between $0.002-0.004 \mu \mathrm{g} \mathrm{L}^{-1}$. The average recoveries of OPCs in beer samples were from $87 \%$ to $98 \%$, which indicates that the reproducibility of the method was satisfactory. Blank analyses were also performed in order to assess the interference from the sample.

The organochlorines concentrations are reported as $\mu \mathrm{g} / \mathrm{L}$. The average concentration of each pesticide was compared to the Code Maximum Residue Limits, MRLs [12]. All determinations were done in triplicates and the results are presented as arithmetic means with standard deviations (SD). 
Health risk assessment

The assessment of the risk for consumers' health represented by the pesticide residues in beer samples, were based on the calculation of lifetime average daily dose (LADD) and hazard quotient (HQ) parameters, according to Kumar et al., [13]. In order to calculate the value of LADD, the following parameters were included: average daily consumption of beer for an adult ( $0.660 \mathrm{~L} /$ day) and average body weight for an adult (70 kg) [14]. To calculate the HQ factor, the reference dose $\left(\mathrm{mg} \mathrm{kg} \mathrm{bw}^{-1} \mathrm{~d}^{-1}\right)$ of analysed OCPs was included [15].

\section{Results and discussions}

\section{Levels of the organochlorine pesticides (OCPs)}

The present study showed the presence of the following organochlorine pesticides (OPC) compounds: $\mathrm{HCB}, \gamma-\mathrm{HCH}$ (lindane), Heptachlor, Drins (Aldrin, Dieldrin, Endrin) and DDTs (p,p' DDE, p,p, DDD and p,p' DDT) in beer samples. The mean values of OPC residues in beer samples are presented in Table 1.

Table 1

LEVELS OF ORGANOCHLORINE PESTICIDES IN BEER SAMPLES $\left(\mu \mathrm{g} \mathrm{L}^{-1}\right)$

\begin{tabular}{|c|c|c|c|c|c|c|c|c|c|}
\hline \multirow[t]{2}{*}{ sample } & \multirow[b]{2}{*}{$\mathrm{HCB}$} & \multirow[b]{2}{*}{$\begin{array}{l}\gamma-\mathrm{HCH} \\
\text { (Lindan) }\end{array}$} & \multirow[b]{2}{*}{ Heptaclor } & \multicolumn{3}{|c|}{ Drins } & \multicolumn{3}{|c|}{ DDTs } \\
\hline & & & & Aldrin & Dieldrin & Endrin & $\begin{array}{l}\text { p,p } \\
\text { DDE }\end{array}$ & $\begin{array}{l}\text { p,p } \\
\text { DDD }\end{array}$ & $\begin{array}{l}\text { p,p } \\
\text { DDT }\end{array}$ \\
\hline 1 & \&LD & ELD & \&LD & $<L D$ & ELD & EDD & ELD & ELD & 0.005 \\
\hline 2 & $\angle L D$ & $\varepsilon \mathrm{LD}$ & 0.005 & $\varepsilon \mathrm{LD}$ & ELD & EDD & ELD & 0.038 & ELD \\
\hline 3 & 0.047 & 0.258 & 0.017 & 0.005 & 0.013 & EDD & 0.037 & $\angle D D$ & EDD \\
\hline 4 & दLD & 0.024 & दD & \&DD & RDD & दD & ELD & ELD & ELD \\
\hline 5 & <LD & <LD & \&DD & ELD & ELD & ELD & ELD & ELD & 0.004 \\
\hline 6 & 0.006 & 0.010 & ELD & ELD & EDD & ELD & \&DD & \&LD & ELOD \\
\hline 7 & 0.008 & 0.017 & 0.004 & ELD & ELD & ELD & \&LD & ELD & 0.007 \\
\hline 8 & दLD & 0.944 & 0.007 & 0.244 & ELD & 0.141 & 0.034 & $\Leftrightarrow D$ & 0.184 \\
\hline 9 & $\angle \mathrm{LD}$ & 0.724 & 0.030 & 0.160 & 0.024 & 0.076 & 0.180 & 0.019 & 0.012 \\
\hline 10 & $\angle L D$ & 0.295 & 0.007 & 0.044 & 0.156 & 0.271 & 0.184 & 0.026 & 0.546 \\
\hline 11 & $\angle L D$ & दOD & 0.059 & 0.027 & 0.070 & 0.033 & ELD & ELD & 0.051 \\
\hline 12 & $\angle L D$ & 0.150 & \&DD & 0.031 & 0.006 & 0.016 & 0.025 & ELD & 0.070 \\
\hline 13 & $\angle \mathrm{LD}$ & 0.893 & \&LD & 0.225 & 0.082 & 0.044 & 0.455 & \&DD & 0.253 \\
\hline 14 & $\angle L D$ & 0.009 & 0.007 & $<\mathrm{LD}$ & \&DD & $<D D$ & \&DD & 0.007 & \&DD \\
\hline 15 & LLD & ELD & 0.012 & ELD & 0.003 & ELD & 0.363 & 0.010 & 0.098 \\
\hline 16 & $\angle L D$ & ELD & \&LD & ELD & \&LD & \&LD & \&LD & 0.006 & \&LD \\
\hline 17 & $\angle L D$ & \&DD & 0.019 & $<\mathrm{LD}$ & $\angle L D$ & 0.004 & 0.038 & 0.011 & 0.044 \\
\hline 18 & $\angle \mathrm{LD}$ & EDD & 0.019 & 0.043 & ELD & <DD & <DD & 0.008 & \&DD \\
\hline 19 & $\angle L D$ & \&DD & $<\mathrm{LD}$ & $<\mathrm{LD}$ & ELD & \&DD & 0.011 & 0.006 & 0.008 \\
\hline 20 & $\angle D D$ & \&DD & 0.025 & 0.013 & ELD & ELD & \&DD & 0.014 & ELD \\
\hline
\end{tabular}

The most active and important isomer of $\mathrm{HCH}, \gamma-\mathrm{HCH}$ (Lindane) was detected in ten samples (50\%) with the concentration ranging between $0.009-0.944 \mu \mathrm{g} \mathrm{L}^{-1}$ and mean concentration being $0.332 \pm 0.024 \mu \mathrm{g} \mathrm{L}^{-1}$. The presence of lindane in analysed beer samples may be because $\gamma-\mathrm{HCH}$ is more resistant to biological and chemical degradation under aerobic conditions and because it is most commonly used [16]. The ration and levels of $\mathrm{HCH}$ isomers are often used as evidence of the past or current technical $\mathrm{HCH}$ application [17]. $\beta-\mathrm{HCH}$ is the most stable isomer and $\alpha-\mathrm{HCH}$ compound is highly volatile and less persistent [18]. In addition, after a long period of weathering, $\alpha-$ and $\gamma-\mathrm{HCH}$ isomers could be transformed into $\beta-\mathrm{HCH}$ compound [19]. Considering that the half-life of lindane in soil is quite short, its past usage cannot be responsible for the currently observed level of contamination. Possibly, high lindane levels resulted from the presence of pesticide "deposits", could be considered a source of secondary contamination of ground waters and soils.

From drins group, aldrin was detected in $45 \%$ of the samples at a mean concentration of $0.088 \pm 0.21 \mu \mathrm{g} \mathrm{L}{ }^{-1}$, while, its metabolite, dieldrin, registered an average of $0.050 \pm 0.017 \mu \mathrm{g} \mathrm{L}^{-1}$, in the analysed beer samples. This may indicate the metabolism of original Aldrin contaminant into dieldrin. In addition, the mean values of endrin detected in analysed samples of $0.073 \pm 0.034 \mu \mathrm{g} \mathrm{L} \mathrm{L}^{-1}$, may be a result of the recent input into the environment. This also suggests less photodecomposition or less microbial degradation of endrin to endrin derivates [20, 21]. 
Although DDT has also been banned in the many countries, its residual concentration could be attributed to the direct use of pesticides available under different chemical name and/or persistence of the insecticide in the environment [22]. DDT and its metabolites can be adsorbed into surface soil or transferred into the aquatic systems and eventually become sediments. It has been estimated that more than 50\% DDT can remain in soil after 10-15 years of its application [23]. From the metabolites of DDT, p,p-DDE is known to be more persistent in the environment, due to the fact that when DDT inlet levels of the environmental ceases, its DDE metabolite levels will be higher than parental DDT.

DDT and its metabolites (p,p'-DDE; p,p' -DDT and p,p'-DDD), were detected in considerable number of samples, in more than $45 \%$ of the samples. A major metabolite of DDT namely 2,2-bis-p-chlorophenyl)-1,1-dichroethylene (p,p DDE) was detected at mean levels of $0.147 \pm 0.010 \mu \mathrm{g} \mathrm{L}^{-1}$, in range of n.d.-0.455 $\mu \mathrm{g} \mathrm{L}^{-1}$. The average concentration levels

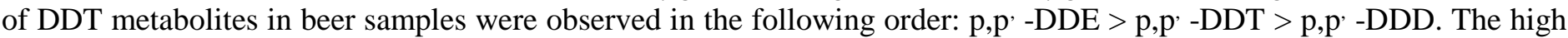
level of the most persistent metabolite ( $\mathrm{p}, \mathrm{p}$ - $-\mathrm{DDE}$ ) indicates that there were no recent sources of DDT for the environment. DDT is known to biodegrade to DDE under aerobic conditions and to DDD in anaerobic conditions [24]. Since DDT is known to undergo metabolic conversion and dehydrochlorination; the presence of its metabolites p, $\mathrm{p}^{\text {' }}$-DDE and p,p' -DDD encountered in this study might be due to such metabolic processes.

In order to identify the possible source of DDT, the DDE and DDD to DDTs ratios have been calculated. Thus, the high ratio of DDE plus DDD to DDT mean values support the assumption that current DDT exposure levels primarily originate from previous contamination and environmental persistency $[22,25]$. In the present study, $25 \%$ of the beer samples had a ratio (DDD + DDE)/ DDTs $>0.5$ showing that both weathered and fresh DDT could represent sources of contamination.

At the same time, positive correlations were observed between DDTs and $\gamma$ - $\mathrm{HCH}(\mathrm{r}=0.782)$, which may indicate longtime persistence of these pesticides in soil, ongoing usage or uncontrolled penetration from some sources.

Hexachlorobenzene (HCB), as a by-product or impure product resulted during the manufacture of pesticides or involuntarily produced by incomplete combustion in municipal solid waste incinerators, was present in $15 \%$ of the samples in proportions ranging from 0.006 to $0.047 \mu \mathrm{g} / \mathrm{L}$. Heptachlor was found at a relatively medium frequency of $15.18 \%$ of total OPCs samples, with an average value of $0.017 \pm 0.009 \mu \mathrm{g} \mathrm{L}{ }^{-1}$, ranging from n.d. to $0.059 \mu \mathrm{g} \mathrm{L}^{-1}$.

Overall, total concentration of $\Sigma$ OCPs ranged between n.d. to $2.637 \mu \mathrm{g} \mathrm{L}^{-1}$, with the mean of $0.875 \mu \mathrm{g} \mathrm{L} \mathrm{L}^{-1}$ (Table 2). It can be seen that $\Sigma \mathrm{HCH}$ (Lindane) and $\Sigma$ DDT concentrations constituted the majority of all detected OCPs, above $75 \%$. Among OCP residues, $\gamma-\mathrm{HCH}$ (Lindane) occurred in the highest concentrations, with an average value of $0.332 \mu \mathrm{g} \mathrm{L}{ }^{-1}$, followed by DDTs, Drins, HCB and heptachlor (figure 1). This is probably due to the use of more technical $\mathrm{HCH}$ (lindane) as regards to technical DDT, before the agricultural uses of these insecticides were banned in 2006. On the other hand, DDT is more hydrophobic than $\mathrm{HCH}$. Hydrophobic compounds are strongly bound to root and soil organic colloidal surfaces resulting in less absorption and translocation [26].

Table 2

PESTICIDE RESIDUE CONCENTRATIONS IN BEER SAMPLES $\left(\mu \mathrm{g} \mathrm{L} \mathrm{L}^{-1}\right)$

\begin{tabular}{|c|c|c|c|c|}
\hline Pesticide & Range & इOCP & Mean $^{8}$ & $\mathrm{SD}^{\mathrm{b}}$ \\
\hline HCB & n.d -0.047 & 0.061 & 0.020 & 0.003 \\
\hline \%-HCH (Lindane) & n.d -0.944 & 3.324 & 0.332 & 0.024 \\
\hline Heptachlor & n.d -0.059 & 0.201 & 0.017 & 0.009 \\
\hline Aldrin & n.d -0.244 & 0.792 & 0.088 & 0.021 \\
\hline Dieldrin & n.d -0.156 & 0.354 & 0.050 & 0.017 \\
\hline Endrin & n.d -0.171 & 0.585 & 0.073 & 0.034 \\
\hline E Drins & n.d -0.571 & 1.731 & 0.238 & 0.081 \\
\hline $\mathrm{p}, \mathrm{p} \cdot \mathrm{DDE}$ & n.d -0.455 & 1.326 & 0.147 & 0.010 \\
\hline $\mathrm{p}, \mathrm{p}, \mathrm{DDD}$ & n.d -0.015 & 0.145 & 0.015 & 0.003 \\
\hline p,p. DDT & n.d -0.546 & 1.275 & 0.106 & 0.049 \\
\hline EDDT & n.d-1.016 & 2.746 & 0.268 & 0.062 \\
\hline Total OPCs & n.d -2.637 & 8.063 & 0.875 & 0.17 \\
\hline
\end{tabular}

n.d $=$ no detection.

${ }^{2}$ Mean of samples where residues were detected

'Standard deviation of mean 


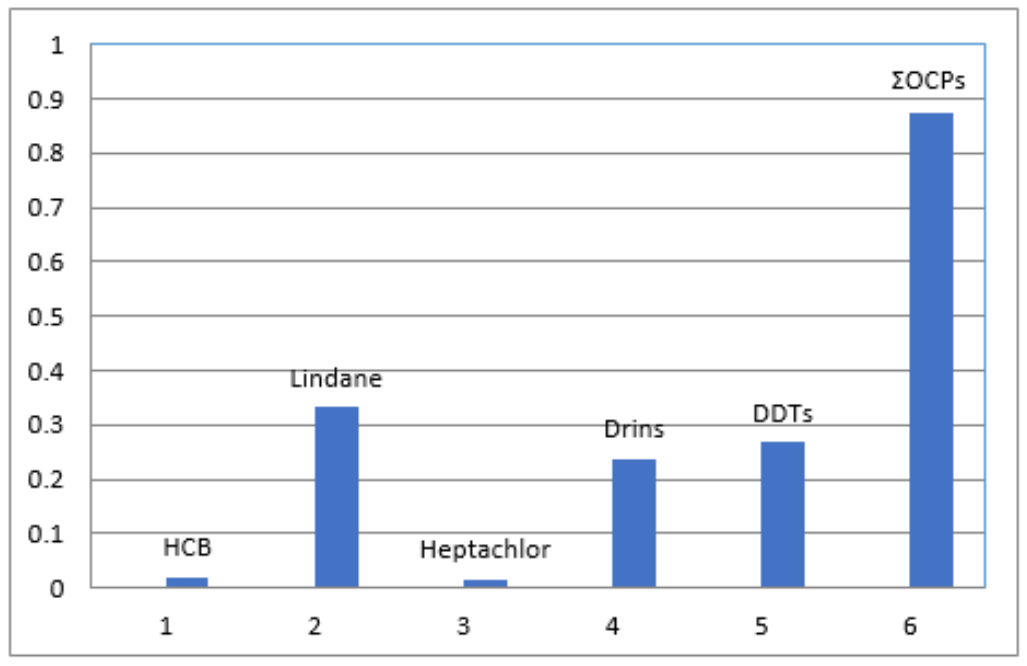

Fig. 1. Average concentration of OCPs $\left(\mu \mathrm{g} \mathrm{L}^{-1}\right)$

\section{Frequency of contamination with the different OCPS}

Generally, the contamination frequency of the examined samples by the organochlorine pesticides followed the order: DDTs $>$ Driens $>$ Heptachlor $>$ Lindane $>$ HCB (figure 2.). Among various OCPs examined in this study, DDTs and Driens are the most prominently noticed compounds, as they were detected at a high frequency. On the other hand, Lindane compound was only present in less than $13 \%$ of the analysed samples, although it was detected in the high concentration. The concentration of OCP compounds in this study was compared to the recommended maximum residue limits (MRLs) and the levels were below their respective values.

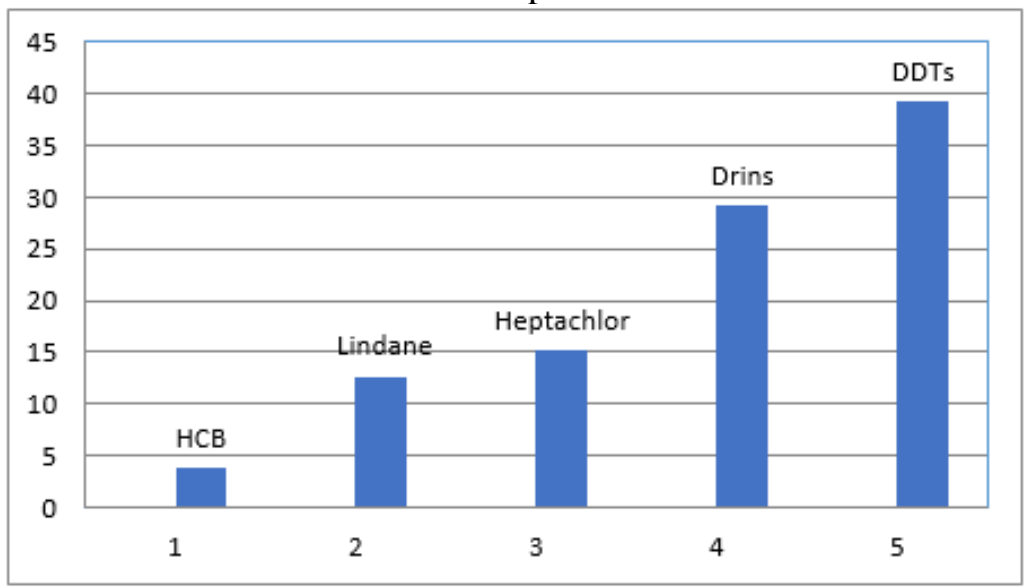

Fig. 2. Percent $(\%)$ of contaminated samples with different OCPs analyzed

Hengel and Shibamoto have shown the presence of pesticides in hops and barley at higher levels as compared to the beer found in our proposed study [27]. This can be due to the fact that during the beer production, pesticide residues which might be present on barley and hops are transferred in beer according to their water partition coefficient $\left(\mathrm{K}_{\mathrm{ow}}\right)$. Water-soluble compounds are more likely to be transferred into the beer whereas more lipophilic compounds are retained in the lipophilic cells and are metabolized by the biotic metabolism of the added yeast, or degraded by abiotic processes from the relative reductive environment, during fermentation. In the manufacturing process, a combination of the malting step, the high dilution with water and the filtering processes, generally result in no detectable residues in beer [28].

OCPs being insoluble compounds, can remain on the malt and after the mashing and boiling processes, they can be passed into the wort in different proportions. In addition, the removal of material in the form of waste and spent grains tends to reduce the level of pesticides [29. 30].

\section{Mass distribution percentage}

The occurrence of pesticide residues is presented in figure 3. All analysed beer samples were contaminated with at least one OCP, but $80 \%$ of the samples had residues of more than one pesticide. A single residue was detected in $20 \%$ of the samples and two, three and four residues in $10 \%, 20 \%$ and $5 \%$ of the samples respectively, while multiple residues were found in $45 \%$ of samples. The most frequently detected compounds were p,p. DDT and heptachlor, in 12 samples; the most frequent combinations of two pesticides detected in the same samples were Lindane and heptachlore (in 6 samples) and pp-DDE and pp-DDT (in 8 samples), respectively. The occurrence of multiple residues in some of the 
analysed samples is likely to be a consequence of the application of different types of pesticides to protect a crop against different insect pests and diseases.

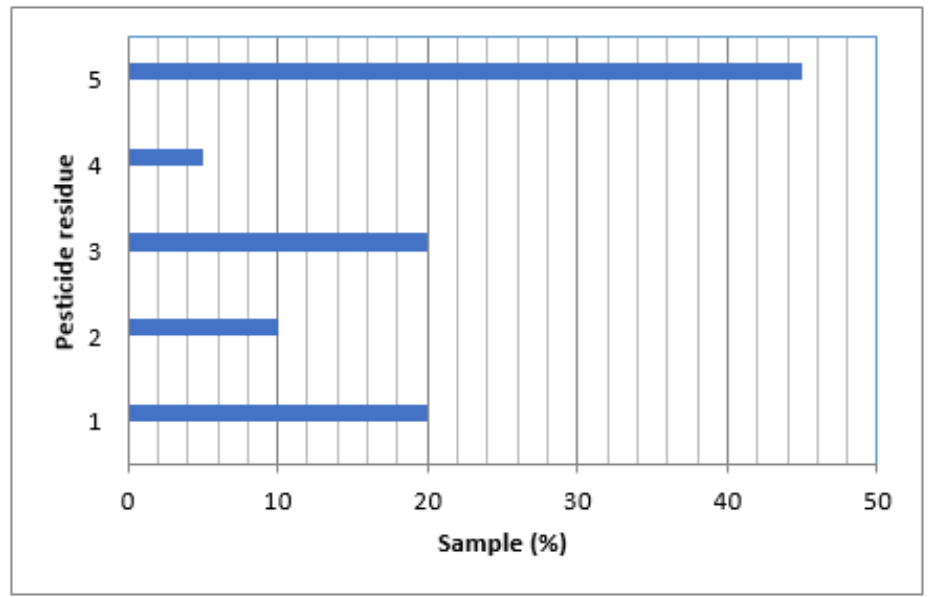

Fig. 3. Beer samples (\%) with multiple residue of pesticides

\section{Health risk estimates for organochlorine pesticides}

In order to estimate the measure of the risk for consumer' health, certain parameters were calculated, such as lifetime average daily dose (LADD) and hazard quotient (HQ). Table 3 presents the estimation of organochlorine pesticides intake through consumption of the beer samples which have been studied. Results indicate that the studied organochlorine pesticides in beer samples belong to the no-risk class. The lifetime average daily dose (LADD) values ranged between 1.41E-07 and 3.13E-06 mg kg bw ${ }^{-1} \mathrm{~d}^{-1}$ and were below the acceptable daily intake (ADI) for particular compounds. Also, the hazard quotient values $(\mathrm{HQ}<1)$ suggests that the OCP residues present in the beer samples represent no threat to human health.

Table 3

HEALTH RISK ESTIMATION FOR ORGANOCHLORINE PESTICIDE RESIDUE IN BEER

\begin{tabular}{|c|c|c|c|c|}
\hline Pesticide & $\begin{array}{c}\text { Acceptable daily } \\
\text { intake (ADI) } \\
\left(\mathrm{mg} \mathrm{kg} \mathrm{bw}^{-1} \mathrm{~d}^{-1}\right)\end{array}$ & $\begin{array}{c}\text { Lifetime average daily dose } \\
\text { (LADD) } \\
\left(\mathrm{mg} \mathrm{kg} \mathrm{bw}^{-1} \mathrm{~d}^{-1}\right)\end{array}$ & $\begin{array}{c}\text { Hazard quotient } \\
\text { (HQ) }\end{array}$ & Health risk. \\
\hline Y-HCH(Lindane) & 0.005 & $3.13 \mathrm{E}-06$ & 0.00062 & No \\
\hline Heptachlor & 0.0001 & $1.60 \mathrm{E}-07$ & 0.0016 & No \\
\hline Aldrin & 0.003 & $8.29 \mathrm{E}-07$ & 0.00027 & No \\
\hline Dieldrin & 0.0001 & $4.71 \mathrm{E}-07$ & 0.00471 & No \\
\hline Endrin & 0.0002 & $6.88 \mathrm{E}-07$ & 0.00344 & No \\
\hline p,p. DDE & 0.01 & $1.38 \mathrm{E}-06$ & 0.00013 & No \\
\hline p,p DDD & 0.01 & $1.41 \mathrm{E}-07$ & 0.000014 & No \\
\hline p,p. DDT & 0.01 & $9.99 \mathrm{E}-07$ & 0.000099 & No \\
\hline
\end{tabular}

\section{Conclusions}

OCPs in twenty (20) beer samples commercially sold in local markets and widely consumed by people have been analysed. It could be concluded that OCP residues were detected in beer samples as they were persistent in nature due to their slow decomposition rate, long half-life and high stability in the environment. Lindane and DDTs were the main contributors to the total OCP residues, suggesting long-time persistence of these pesticides in soil, ongoing usage or uncontrolled penetration from other sources. Based on the mass distribution percentages of OCPs, a single residue was detected in $20 \%$ of the samples and multiple residues were found in $45 \%$ of samples. In all cases, the values of detected OCPs were below the tolerance levels of FAO/WHO. The lifetime average daily dose (LADD) for the total compounds under study was below the acceptable daily intake (ADI) for individual compounds. Also, hazard quotient was presented with very low values $(\mathrm{HQ}<1)$, suggesting that, in the analysed samples, the OCP residues represent no threat to human health. 


\section{References}

1.NAVARRO, S., VELA, N., Beer in Health and Disease Prevention, Fate of Pesticide Residues During Brewing. 2005, Academic Press. www.elsevierdirect.com

2.FAO, The state of food insecurity in the world. Food and Agriculture Organization of the United Nations., 2004, Rome, Italy.

3.LEVITAN, L., Crop Protection. 19, 2000, p. 629.

4.SKEVAS, T., OUDE LANSINK, A.G., STEFANOU, S.E., Wageningen Journal of Life Sciences, 64, 2013 , p. 95.

5.MEGHESAN - BREJA, A., MARUTOIU, C., CIMPOIU, C., Rev. Chim. (Bucharest), 66, no. 1, 2015, p. 32.

6.SHARIF, Z., MAN, Y.B.C., HAMID, N.S.A., KEAT, C.C., J Chrom A. 1, 2006, p. 254.

7.FATTORE, E., FANELLI, R., VECCHIA, C.L., J. Epidemiol. Comm. Health, 56, 2002, p. 831.

8.MOHAMMED, M., BOATENG, K.K., Pollution, 3, no. 1, 2017, p. 69.

9.SOCEANU, A., DOBRINAS, S., STANCIU, G., VIORICA POPESCU, V., EPURE, D.E., Rev. Chim. (Bucharest), 63, no. 5, 2012 , p. 455.

10.WITCZAK, A., POHORYLO, A., MITUNIEWICZ-MALEK, A., Chemosphere 148, 2016, p. 395.

11.DETI, H., HYMETE, A., BEKHIT, A.A., MOHAMED, A.M.I., BEKHIT, A.E.D.A., Chemosphere, 106, 2014 , p. 70.

12.FAO/WHO, 2013. Pesticide Residues in Food and Feed, Codex Alimentarius Commission, Joint FAO and WHO Food Standard Programme., Rome, Italy.

13.KUMAR, B., MISHRA, M., VERMA, V.K., KUMAR, S., SHARMA, C.S., 2013. J. Xenobiotics, 3, no. 1, 2013 , p. 1.

14.Beer, Health and Nutrition Studies, Central statistical Office, Bucharest, 2017.

15.EPA,. National Recommended Water Quality Criteria: In: Human Health Criteria Calculation Matrix. US Environmental Protection Agency), 2002.

16.EL BEIT, I.Q., WHEELOCK, V., COTTON, D.E., Ecotoxicology and Environmental Safety, 5 no. 2, 1981, p. 135.

17.JAFARI, A., MOECKEL, C., JONES, K.C., J. Environ. Monit. 10, 2008, p. 861.

18.WILLETT, K.L., ULRICHI, E.M., HITES, R.A., Env. Sci. Technol., 32, no. 15, 1988, p. 2197

19.YANG, R.Q., JIANG, G.B., ZHOU, Q.F., YUAN, C.G. SHI, J.B., Environmental International 31, 2005 , p. 799.

20.BEMPAH, C. K., DONKOR, A. K., Environ. Monit. Assess. 175, 2010, p. 1.

21.ATSDR (2002). Toxico profile for aldrin and dieldrin. US Department of Health and Human Services, Public Health Service, Atlanta, GA. US Dept. Health Hum.

22.HOVAANSZKIN, D., PROKISCH, J., GYORI, Z., Cereal Research Communications, 35, no. 2, 2007, p. 493.

23.YANG, Y., LI, D., MU, D., Atmosph. Environment, 42, no. 4, 2007, p. 677.

24.BARRIADA-PEREIRA, M., GONZALEZ-CASTRO, M. J., MUNIATEGUE-LORENZO, S., LOPE-MAHIA, P., PRADA-RODRIGUEZ, D., FERNANDEZ, E., 2005. Chemosphere 58, 2005, p. 1571.

25.NTOW, W. J., Arch. Environ. Contam. Toxicol. 40, 2001, p. 557.

26.PEREIRA, R.C.M., CAMPS-AEBESTAIN, B., GARRIDO, R., MACIAS, F., MONTERROSO, C., Env. Pollution 44, 2006 , p. 210.

27.HENGEL, M.J. SHIBAMOTO, T., J. Agric. Food Chem. 50, 2002, p. 3412.

28.NAVARRO, S., PEREZ, G., NAVARRO, G., MENA, L., VELA, N., J. Food Prot. 69, no. 7, 2006, p. 1699.

29.NAVARRO, S., PEREZ, G., VELA, N., MENA, L., NAVARRO, G., J. Agric. Food Chem. 53, 2005, p. 8572.

30.NTOW, W.J., Reservoirs Research \& Management, 10, no. 4, 2005, p. 243.

$\overline{\text { Manuscript received: } 14.12 .2018}$ 
